\title{
Does Neurally Adjusted Ventilatory Assist Compared to Pressure Support Ventilation Decrease Patient Ventilator Asynchrony?
}

\author{
Hussam Abd Elfatah Mohamed*, Mohamed Amin Fakher, Moemen Arafa, Khaled Abdel Wahab Selem, Alia Abdel Fatah \\ Department of Critical Care, Cairo University, Cairo, Giza, Egypt
}

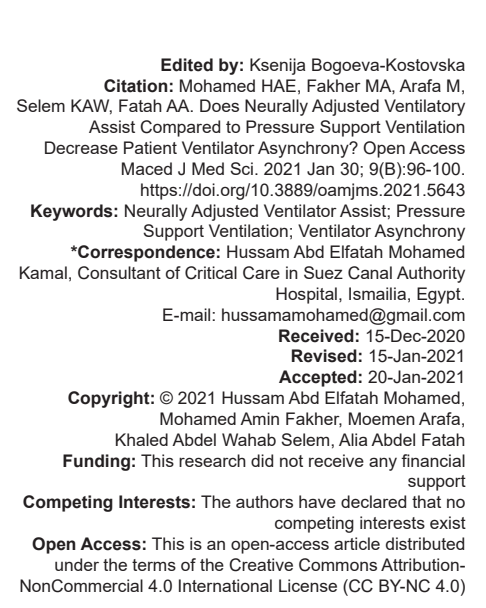

\begin{abstract}
BACKGROUND: Patient-mechanical ventilator (MV) asynchrony despite optimal adjustment of MV parameters is a common problem that is partly associated with difficult weaning of MV. Neurally adjusted ventilatory assist (NAVA) is a mode of proportional ventilation that count on diaphragmatic activity (measured by special esophageal probe and expressed as diaphragm electrical [Edi]) to provide proportional support to patient effort which differs from one breath to another according to Edi signal.

AIM: The purpose of this trial is to determine the impact of NAVA compared to pressure support ventilation (PSV) mode in decreasing patient-MV asynchrony and hemodynamic effect in patients on MV with expected difficult weaning.

MATERIALS AND METHODS: This prospective interventional trial was conducted on 30 critically ill on MV with expected difficult weaning. First, patients were put on PSV mode for $24 \mathrm{~h}$. Then, patients were put on NAVA mode (for weaning) for the next $24 \mathrm{~h}$. The incidence of different types of asynchrony in both modes was investigated.

RESULTS: NAVA mode significantly reduced the asynchrony index when compared to PSV $(1.1 \pm 0.39 \%$ vs. $2.8 \pm 1.1$ respectively, $p<0.001$ ), P/F ratio was significantly higher during NAVA (250 in NAVA vs. 210 in PSV, $p<0.001$ ), heart rate, and mean arterial blood pressure were significantly reduced during NAVA ( $p<0.001$ and 0.015 , respectively).

CONCLUSIONS: Compared to PSV, NAVA-reduced patient-MV asynchrony significantly and increased the P/F ratio significantly with better hemodynamics.
\end{abstract}

\section{Introduction}

In the intensive care unit (ICU), usage of partial ventilatory support is increasing using pressure support ventilation (PSV) most widely. Regardless the inspiratory effort of patient, a predetermined pressure with PSV is given to assist inspiration. Asynchrony between the degree of assist and respiratory drive of patient may be potentially harmful causing respiratory discomfort and patient-mechanical ventilator (MV) asynchrony which are responsible for difficult weaning and prolonged MV duration [1].

Neurally adjusted ventilatory assist (NAVA) delivers ventilation proportionally by the use of esophageal probe which detects the diaphragm electrical activity (EAdi) that triggers the ventilatory cycle and then deliver proportional pressure according to patient effort [2]. Hence, the pressure support differs proportionally according to EAdi signal from cycle to cycle [3].

Definition of difficult weaning is spontaneous breathing trial failure or resumption of MV within 48 $\mathrm{h}$ from its removal [2]. It is responsible for higher MV duration and ICU stay length [4]. The increase in MV duration leads to higher morbidities and mortalities in the ICU as higher MV duration is a risk factor for developing ventilator-associated pneumonia [5].

Weaning problems are partially correlated with the occurrence of asynchronies between the patient and the MV that arise where either the start and/or cessation of the MV does not satisfy neural inspiration in time or where the severity of the mechanical assistance may not fulfill the patient's respiratory requirements.

Asynchrony between the MV and patient may lead to difficult weaning. Asynchrony happens when the neural inspiration is not coincident with either the beginning and/or end of the breath given by $\mathrm{MV}$, or when the respiratory demands of patient is not meet by the MV assist [6]. Asynchrony can be in the form of ineffective effort, auto-triggering, premature cycling, double triggering delayed cycling, and auto-positive end expiratory pressure (auto-PEEP) [6]. These asynchronies may persist despite optimal adjustment of the MV settings [6].

The purpose of this trial is to determine the impact of NAVA compared to PSV mode in decreasing patient-MV asynchrony and hemodynamic effect in patients on MV with expected difficult weaning. 


\section{Materials and Methods}

This prospective interventional trial was approved by the local Ethics and Research Committee before inclusion of patients. Informed consent was taken from patients and/or families (next of kin).

The study was conducted on patients on MV with expected difficult weaning [7] in the ICU from June 2017 to August 2018. Definition of difficult weaning is a high MV duration, or respiratory (restrictive or chronic obstructive pulmonary diseases), cardiac (coronary artery disease or heart failure), or neuromuscular diseases [7].

Thirty patients were allocated in the trial when they met the general and respiratory criteria for PSV after stopping sedation.

Exclusion criteria were patients with tracheotomy, a progressive infection (e.g., pneumonia), contraindication to placement of EAdi catheter (e.g., esophageal varices and recent surgery in the stomach or esophagus) and/or hemodynamic instability (mean arterial blood pressure (MAP) $<65 \mathrm{mmHg}$ with or without vasopressors requirement).

First, patients were put on PSV mode for $24 \mathrm{~h}$. Then, patients were put on NAVA mode (for weaning) for the next $24 \mathrm{~h}$. The MV settings were adjusted to decrease the asynchrony.

In PSV mode, the inspiratory trigger in-flow, pressure support level were adapted to achieve 6-8 ml/ $\mathrm{kg}$ of predicted body weight (PBW) tidal volume (VT), and external PEEP adapted to intrinsic PEEP level and expiratory cycling. Pressure support level was adjusted to obtain the VT but both expiratory and inspiratory triggers were put steady during measurement.

In NAVA mode, Servo-i ${ }^{\circledR}$ (preview NAVA) MV estimated the NAVA gain to deliver the equal peak pressure as with PSV which was not changed during the study measurement in most cases. The EAdi inspiratory trigger was put to at $0.5 \mu$ volts which mostly more than the EAdi of the patient minimal value. The cycle-off value was fixed at $70 \%$ of peak EAdi in the NAVA mode. As PEEP was adjusted in PSV, PEEP in NAVA was the same.

Among those patients, we compared the incidence of different types of desynchronies during period of PSV versus NAVA.

Volume, pressure and flow curves, VT, and support level were recorded. Hemodynamic and P/F ratio were also, recorded during both NAVA and PSV.

\section{Data analysis}

Analysis of respiratory curves was done by analysis of the $1^{\text {st }} 5$ min of recording every $4 \mathrm{~h}$ manually with a total 30 min duration of analysis.

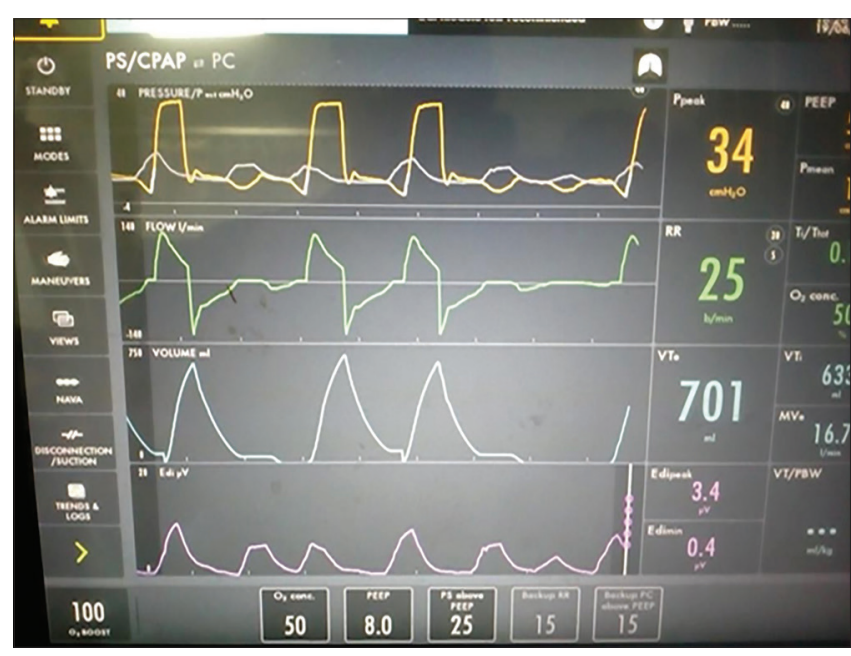

Figure 1: Ineffective effort during pressure support ventilation

Asynchronies types were: (a) Ineffective efforts defined by the existence of an EAdi signal, without a MV cycle (Figure 1), (b) auto-triggering defined by the presence of a MV cycle without a diaphragmatic signal (Figure 2), (c) double triggering, this was defined by the presence of two successive cycles without intermediate expiration or an interrupted exhalation, or by a biphasic aspect of the EAdi signal, which leads to two successive machine cycles (Figure 3). (d) Auto-PEEP defined as the flow curve does not return to base line (Figure 4) delayed cycling defined as termination of neural breath earlier than mechanical breath [8].

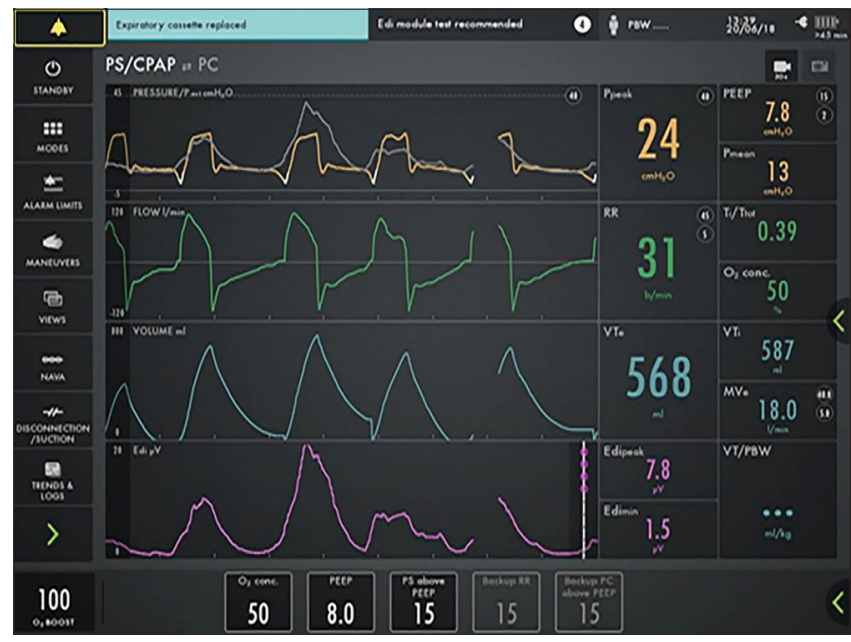

Figure 2: Auto-triggering during pressure support ventilation

Calculation of asynchrony index (AI) was number of asynchronies/number of EAdi signals * 100 . The same was performed for types of asynchronies: Number of each asynchrony events/total number of cycles over the period analyzed * 100 [8].

\section{Statistical analysis}

Data analysis was performed by SPSS version $22\left(\right.$ IBM $^{\odot}$, Chicago, USA). The characteristics of the population and the variables are shown as mean \pm standard deviation, median, and inter quartile 


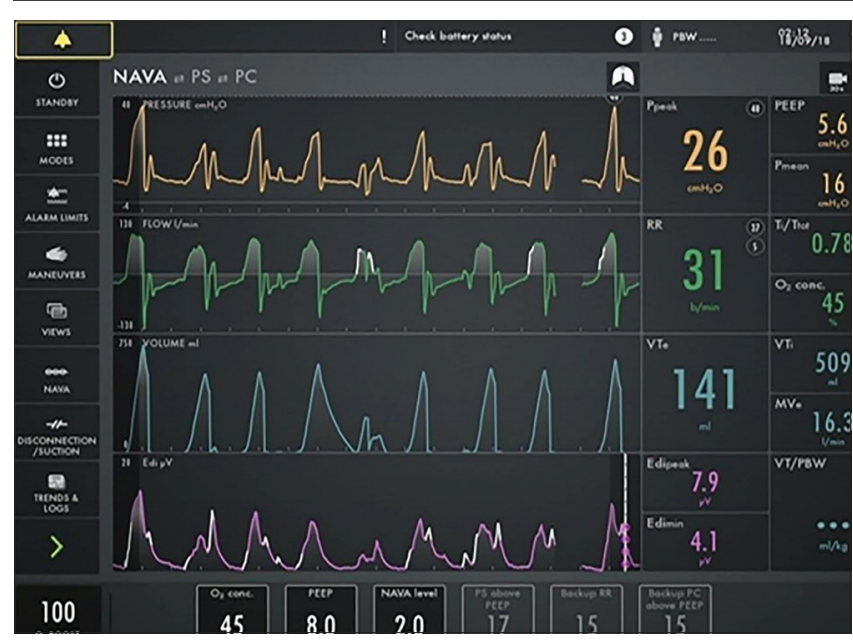

Figure 3: Double triggering during neurally adjusted ventilatory assist

for abnormally distributed data. Comparisons between groups were done using unpaired t test in normally distributed quantitative variables while Mann-Whitney test was used for non-normally distributed quantitative variables. For comparison of categorical data, Chi square or Fisher's exact test was performed. The cutoff of statistical significance was adopted at $p<0.05$.

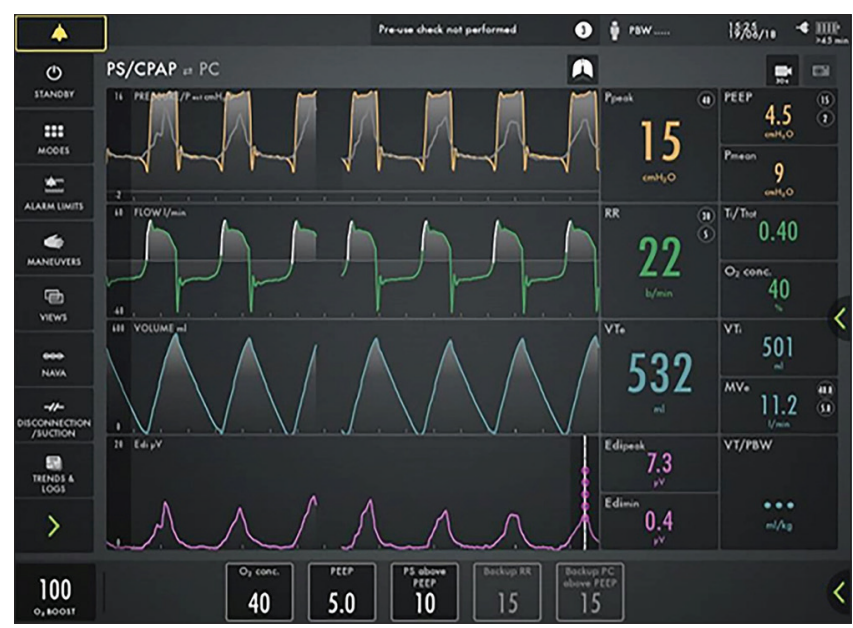

Figure 4: Auto-positive end-expiratory pressure during pressure support ventilation

\section{Results}

The mean age of our patients was $59.2 \pm 17.5$ years, $16(53.3 \%)$ patients were male and $14(46.7 \%)$ patients were female. Known pulmonary disease was in $33.3 \%$, known cardiac disease was in $46 \%$, and known chronic kidney disease was in 33\% (Table 1).

The mean duration of MV was $16 \pm 7.8$ days, the length of ICU stay was $19.7 \pm 7.7$ days, and APACHE II was $19.7 \pm 8.3$ while $28^{\text {th }}$ day mortality was 40\% (Table 1).

The results of different types of asynchronies showed that ineffective effort, auto-triggering, and delayed cycling were significantly lower during NAVA than PSV with $p$ values $0.004,0.019$, and $<0.001$, respectively, while double triggering was higher during NAVA but with insignificant $p=0.137$. Auto-PEEP was higher during PSV but with insignificant $p=0.49$ (Table 2).

Table 1: Patients' characteristics of the studied group

\begin{tabular}{ll}
\hline Age (years) & $59.2 \pm 17.5$ \\
Sex (male/female) & $16(53.3 \%) / 14(46.7 \%)$ \\
Co-morbidities & \\
$\quad$ Pulmonary disease & $10(33.3 \%)$ \\
Cardiac disease & $14(46 \%)$ \\
$\quad$ Chronic kidney disease & $10(33.3 \%)$ \\
Duration of ventilatory support (days) & $16 \pm 7.8$ \\
Length of ICU stay (days) & $19.7 \pm 7.7$ \\
APACHE II & $19.7 \pm 8.3$ \\
$28^{\text {th }}$ day mortality & $12(40 \%)$ \\
\hline
\end{tabular}
Data are presented as mean $\pm S D$ or frequency (\%); ICU: Intensive care unit.

There was significant reduction of $\mathrm{Al}$ during NAVA mode (A.I $1.1 \pm 0.39 \%$ ) compared to PSV mode (A.I $2.8 \pm 1.1 \%$ ) with $p<0.001$ (Table 2).

Our results showed no significant difference in VT in both NAVA and PSV with $p=0.42$ (Table 2).

Table 2: Ventilatory settings of both modes

\begin{tabular}{llll}
\hline Parameters & $\mathrm{PSV}(\mathrm{n}=30)$ & $\mathrm{NAVA}(\mathrm{n}=30)$ & $\mathrm{p}$-value \\
\hline Level of support & $16.1 \pm 2.8 \mathrm{cmH}_{2} \mathrm{O}$ & $1.3 \pm 0.36 \mathrm{cmH}_{2} \mathrm{O} / \mu$ volt & ---- \\
Asynchrony index $(\%)$ & $2.8 \pm 1.1$ & $1.1 \pm 0.39$ & $<0.001$ \\
Ineffective efforts $(\%)$ & $0.9(0.35-1.28)$ & $0.1(0-0.15)$ & 0.004 \\
Auto-triggering $(\%)$ & $0.66(0-1.05)$ & $0(0-0.1)$ & 0.019 \\
Double triggering (\%) & $0.3(0-0.81)$ & $0.8(0.6-1)$ & 0.137 \\
Delayed cycling (\%) & $0.15(0-0.5)$ & $0(0-0)$ & $<0.001$ \\
Auto-PEEP & $2(6.67 \%)$ & 0 & 0.492 \\
Tidal volume (ml/kg of PBW) & $6.7 \pm 1.3$ & $6.5 \pm 0.99$ & 0.42 \\
\hline Data are presented as mean \pm SD, median (IQR) or frequency (\%); PBW: Predicted body weight; Auto- \\
PEEP: Auto-positive end expiratory pressure
\end{tabular}

Our results showed that $\mathrm{P} / \mathrm{F}$ ratio was significantly higher during NAVA than PSV $(258 \pm 31.4$ vs. $210 \pm 37.2)$ with $p<0.001$, While there was no significant difference regarding $\mathrm{pH}, \mathrm{PaCO}_{2}$, and $\mathrm{HCO}_{3}$ with $p$ value $0.57,0.92$, and 0.35 , respectively (Table 3 ).

Table 3: Arterial blood gases (ABGs) and hemodynamics during both modes

\begin{tabular}{llll}
\hline Parameters & $\mathrm{PSV}(\mathrm{n}=30)$ & $\mathrm{NAVA}(\mathrm{n}=30)$ & $\mathrm{p}$ \\
\hline $\mathrm{pH}$ & $7.4 \pm 0.8$ & $7.4 \pm 0.3$ & 0.57 \\
$\mathrm{PaO}_{2} / \mathrm{FiO}_{2}$ & $210 \pm 37.2$ & $258 \pm 31.4$ & $<0.001$ \\
$\mathrm{PaCO}_{2}(\mathrm{mmHg})$ & $38.6 \pm 4.5$ & $40 \pm 2$ & 0.92 \\
$\mathrm{HCO}_{3}(\mathrm{mmol} / \mathrm{L})$ & $21.2 \pm 2.6$ & $22.4 \pm 1.5$ & 0.35 \\
$\mathrm{MAP}(\mathrm{mmHg})$ & $78 \pm 9.8$ & $74 \pm 6.6$ & 0.015 \\
Heart rate (beats/min) & $108 \pm 14.5$ & $88 \pm 7.7$ & $<0.001$ \\
\hline \multicolumn{2}{l}{ Data are presented as mean $\pm \mathrm{SD} ;$ MAP: Mean arterial blood pressure }
\end{tabular}

Our results showed that mean heart rate was significantly reduced during NAVA $(88 \pm 7$ beats $/ \mathrm{m})$ than during PSV $(108 \pm 14.5$ beats $/ m)$ with $p<0.001$. Furthermore, MAP was significantly lower during NAVA $(74 \pm 6.6 \mathrm{mmHg})$ than during PSV $(78 \pm 9.8 \mathrm{mmHg})$ with $p=0.015$ (Table 3).

\section{Discussion}

Regarding patient-MV asynchrony $\mathrm{Al}$, our results were in concordant to Demoule et al. [9] who showed that the Al was significantly decreased with NAVA mode (A.I 14.7\%) than during PSV mode (A.I $26.7 \%$ ) with significant $p<0.001$. Furthermore, Ferreira et al. [10] were in concordant to our results and showed 
that NAVA decreased Al, with a median of $11.5 \%$ compared to $24.3 \%$ in PSV with significant $p=0.033$. Yonis et al. results were also, in concordant to ours which showed that the incidence of double triggering was higher during NAVA in comparison to PSV $(0.76$ vs. 0.71) with $p=0.046$, However, the overall Al was also, decreased in NAVA in comparison to PSV (1.73 vs. 3.36) with highly significant $p<0.001$ [11].

The same was Lamouret et al. who showed that the total AI was lower in NAVA than in PSV mode: $2.1 \%$ versus $14 \%$ with highly significant $p<0.0001$ [12].

Our results were unlike Vagheggini et al. who conducted study on 13 tracheostomized patients with prolonged ventilation and ineffective triggering were evaluated at the highest level of assistance during the last $3 \mathrm{~min}$ of recording then ineffective triggering index as the number of ineffective efforts divided by the total respiratory rate was calculated [13]. Vagheggini et al. showed that there was no significant difference regarding ineffective effort in both NAVA and PSV (4.86 \pm 2.53 vs. $5.00 \pm 2.5$ ) with $p=0.56$. Ineffective effort exceeds $10 \%$ in only one patient on PSV which was insignificant [13].

Regarding hemodynamics, our results were unlike Yonis et al. study that showed non-significant differences in heart rate and MAP between the two modes with non-significant $p$ value $(0.4$ and 0.23 , respectively) [11].

Regarding ABG parameters, our results was in concordant to Yonis et al. study which showed that $\mathrm{PaO}_{2}$ and $\mathrm{PaO}_{2} / \mathrm{FiO}_{2}$ were significantly higher during the NAVA mode compared with PSV (both $p<0.001$ ). While there were no significant difference in $\mathrm{pH}$, $\mathrm{PaCO}_{2}$ and $\mathrm{HCO}_{3}$ with $\mathrm{p}=0.3,0.48$ and 0.12 , respectively [11]. Furthermore, Ferreira et al. showed no significant difference in $\mathrm{pH}$ and $\mathrm{PaCO}_{2}$ with $\mathrm{p}=0.94$ and 0.188 , respectively [10]

Regarding MV parameters, our results come in concordant to Yonis et al. study that showed no significant difference in VT in both modes with $p=0.48$ [11]. Furthermore, Ferreira et al. that showed no significant difference in VT in both modes with $p=0.076$ [10]. Unlike our results Vagheggini et al. said that NAVA prevent over distention as increasing the level of assistance resulted in VT in PSV but not in NAVA with $p=0.001$ [13]. Unlike our results also, Lamouret et al. showed that the VT was lower in NAVA than in PSV (5.8 vs. $6.2 \mathrm{ml} / \mathrm{kg}$ ) with significant $p<0.001$ [12].

\section{Conclusions}

Compared to PSV, NAVA reduced patient-MV asynchrony significantly and increased the $\mathrm{P} / \mathrm{F}$ ratio significantly. While other $A B G$ parameters such as $\mathrm{pH}$,
$\mathrm{PaCO}_{2}$, and $\mathrm{HCO}_{3}$ showed no significant differences after using both modes. NAVA had significant impact on patient hemodynamics which was represented by lower heart rate and MAP.

\section{What is already know on this topic}

1. Patient - MV asynchrony despite optimal adjustment of MV parameters is a common problem that is partly associated with difficult weaning of MV

2. Difficult weaning is responsible for higher MV duration and ICU stay length. The increase in MV duration leads to higher morbidities and mortalities in the ICU.

\section{What this study adds}

1. NAVA reduced patient-MV asynchrony significantly and increased the P/F ratio significantly compared to PSV

2. NAVA had significant impact on patient hemodynamics which was represented by lower heart rate and MAP.

\section{References}

1. Esteban A, Ferguson ND, Meade MO, Frutos-Vivar F, Apezteguia C, Brochard L, et al. Evolution of mechanical ventilation in response to clinical research. Am J Respir Crit Care Med. 2008;177(2):170-7. https://doi.org/10.1164/ rccm.200706-893oc

PMid:17962636

2. Lellouche F. Quelle technique d'humidification pour la ventilation invasive et non invasive? Réanimation. 2016;25:35-55. https:// doi.org/10.1007/s13546-015-1131-x

3. Schmidt M, Demoule A, Cracco C, Gharbi A, Fiamma MN Straus C, et al. Neurally adjusted ventilatory assist increases respiratory variability and complexity in acute respiratory failure. Anesthesiology. 2010;112(3):670-81. https://doi.org/10.1097/ aln.0b013e3181cea375

PMid:20179505

4. Thille AW, Rodriguez P, Cabello B, Lellouche F, Brochard L. Patient-ventilator asynchrony during assisted mechanical ventilation. Intensive Care Med. 2006;32(10):1515-22. https:// doi.org/10.1007/s00134-006-0301-8

PMid:16896854

5. Garrard CS, A'Court CD. The diagnosis of pneumonia in the critically ill. Chest. 1995;108 (2 Suppl):17S-25. https://doi. org/10.1378/chest.108.2_supplement.17s

PMid:7634922

6. Blanch L, Villagra A, Sales B, Montanya J, Lucangelo U, Luján $\mathrm{M}$, et al. Asynchronies during mechanical ventilation are associated with mortality. Intensive Care Med. 2015;41(4):63341. https://doi.org/10.1007/s00134-015-3692-6 PMid:25693449

7. Spadaro S, Mirabella L, Volta CA, Serio G, Staffieri F, Dambrosio $\mathrm{M}$, et al. Impact of prolonged assisted ventilation 
on diaphragmatic efficiency: NAVA versus PSV. Crit Care. 2015;20:1. https://doi.org/10.1186/s13054-015-1178-0 PMid:26728475

8. Longhini F, Ferrero F, De Luca D, Cosi G, Alemani M, Colombo D, et al. Neurally adjusted ventilatory assist in preterm neonates with acute respiratory failure. Neonatology. 2015;107(1):60-7. https://doi.org/10.1159/000367886

PMid:25401284

9. Demoule A, Clavel M, Rolland-Debord C, Perbet S, Terzi N, Kouatchet $A$, et al. Neurally adjusted ventilatory assist as an alternative to pressure support ventilation in adults: A French multicentre randomized trial. Intensive Care Med. 2016;42(11):1723-32. https://doi.org/10.1007/ s00134-016-4447-8

PMid:27686347

10. Ferreira JC, Diniz-Silva F, Moriya HT, Alencar AM, Amato MB, Carvalho CR. Neurally adjusted ventilatory assist (NAVA) or pressure support ventilation (PSV) during spontaneous breathing trials in critically ill patients: A crossover trial. BMC Pulm Med. 2017;17(1):139. https://doi.org/10.1186/s12890-017-0484-5
PMid:29115949

11. Yonis $\mathrm{H}$, Crognier L, Conil JM, Serres I, Rouget A, Virtos M, et al. Patient-ventilator synchrony in neurally adjusted ventilatory assist (NAVA) and pressure support ventilation (PSV): A prospective observational study. BMC Anesthesiol. 2015;15:117. https://doi.org/10.1186/s12871-015-0091-z PMid:26253784

12. Lamouret $\mathrm{O}$, Crognier L, Vardon Bounes F, Conil JM, Dilasser C Raimondi $\mathrm{T}$, et al. Neurally adjusted ventilatory assist (NAVA) versus pressure support ventilation: Patient-ventilator interaction during invasive ventilation delivered by tracheostomy. Crit Care. 2019;23(1):2. https://doi.org/10.1186/s13054-018-2288-2 PMid:30616669

13. Vagheggini G, Mazzoleni S, Vlad Panait E, Navalesi P, Ambrosino N. Physiologic response to various levels of pressure support and NAVA in prolonged weaning. Respir Med. 2013;107(11):1748-54. https://doi.org/10.1016/j. rmed.2013.08.013

PMid:24035203 